Revista de Derecho

de la Pontificia Universidad Católica de Valparaíso

LV (Valparaíso, Chile, 2do semestre de 2020)

[pp. 65-97 ]

\title{
LA SANA CRÍTICA EN MATERIA PENAL, LABORAL Y DE DERECHO DE FAMILIA. VARIACIONES NORMATIVO- INSTITUCIONALES*
}

\author{
[Sound Critism in Penal, Labor and Family Law. \\ Normative-Institutionals, Variations] \\ JOHANN S. BENFELD E. **
}

\begin{abstract}
RESUMEN
La sana crítica es el sistema general de ponderación de la prueba en materia penal, laboral y de familia. Sin embargo, las variaciones normativas, con incidencia probatoria, que es posible hallar en cada uno de los campos precedentes, produce algunas dudas respecto a la homogeneidad del sistema. En tal sentido, aunque se mantiene en las tres materias una nomenclatura común, incluso una caracterización canónica compartida, la forma en que legislativamente se ha implementado la sana crítica no resulta ser siempre coincidente; cuestión que lleva a la pregunta sobre si la manera en que hasta el momento una parte mayoritaria de la doctrina entiende la sana crítica es la adecuada para su comprensión.
\end{abstract}

\begin{abstract}
Sound criticism is the general system of valuation of evidence in criminal, labor and family law. But some normative variations in those areas generate some dubs about homogeneity of the system. Though in criminal, labor and family law there is a same canonical tradition about the sound criticism, the way in that sound criticism has been normatively implemented is not always the same. And this arise the following question: the way in that some important part of doctrine understand until now the sound criticism is in fact the best way to understand it.
\end{abstract}

* La presente investigación ha sido realizada dentro de la ejecución del Proyecto Fondecyt Regular no 1200232, denominado: "El derecho en los hechos. Formulación de un concepto normativo-jurídico de sana crítica como sistema institucional de ponderación libre de la prueba judicial". Grupo de investigación Ciencias Jurídicas y Ciencias Políticas. Investigador responsable: Johann Benfeld. Proyecto financiado por el Fondo de Desarrollo Científico y Tecnológico de Chile (ANID). Agradezco especialmente a don Camilo Gómez Aliste por haberme ayudado en la elaboración del cuadro comparativo que aparece en este artículo y, asimismo, por haberme dado a conocer el caso judicial que al final de estas páginas se comenta a modo ejemplar.

** Licenciado en Ciencias Jurídicas y Filosofía PUCV; Doctor en Derecho por la Universidad de Salamanca, España. Profesor del Departamento de Filosofía y Teoría del Derecho de la Escuela de Derecho de la Pontificia Universidad Católica de Valparaíso. ORCID: https://orcid.org/0000-0001-6109-3878. 
Palabras clave

Derecho probatorio - normas reguladoras de la prueba - ponderación de la prueba - prueba de los hechos -sana crítica.

\section{KeYwords}

Evaluating evidence - evidence law - proof of the facts - regulative rules of evidence - sound criticism.

Recibido el 30 de septiembre de 2020 y ACEPTADO el 31 de enero de 2021

\section{Planteamiento de la Cuestión}

En nuestro sistema procesal probatorio es posible distinguir con claridad dos regímenes generales. Uno de prueba preeminentemente tasada y otro denominado de sana crítica o prueba libre. Entre uno y otro, por cierto, hay espacio para algunas combinaciones normativas (sistemas mixtos, que en la práctica constituyen la regla general en materia probatoria), aunque en este momento las dejaremos de lado.

La tendencia, con todo, es la de la prevalencia del sistema de ponderación mediante la sana crítica y el abandono progresivo (aunque no absoluto) del régimen de tarifa legal. Prueba de ello es el último proyecto de Código Procesal Civil de 2012, que dispone en su artículo 295, sobre valoración de la prueba, que "salvo que la ley atribuya un valor determinado a un medio probatorio, el juez apreciará la prueba de acuerdo a las reglas de la sana critica. En consecuencia, deberá estarse a los principios de la lógica, las máximas de la experiencia y los conocimientos cientificamente afianzados, salvo texto legal que expresamente contemple una regla de apreciación diversa". Norma que debidamente articulada con el artículo 14 del mismo proyecto (aplicación general y supletoria del procedimiento ordinario civil) da como resultado la consagración de un nuevo régimen legal general y supletorio de ponderación de la prueba conforme a la sana crítica. Y aunque la reforma aún no se ha producido, ésta es percibida todavía como una verdadera necesidad ${ }^{1}$.

De momento, la sana crítica sigue, en todo caso, colonizando progresi-

\footnotetext{
1 "Tenemos como Estado una tarea pendiente: el nuevo Código Procesal Civil. El proyecto de ley en trámite en el Congreso pretende estandarizar y brindar coherencia a nuestro sistema procesal, estableciendo los criterios mínimos que se exigen a todo sistema de justicia como lo son la oralidad, inmediación, valoración de la prueba de acuerdo con las reglas de la sana crítica, concentración y publicidad, entre otros... Dicho esto, y sin perjuicio del tiempo transcurrido desde la paralización de la tramitación del proyecto de ley respectivo, la Corte Suprema es optimista y se resiste a asumir un rol pasivo en la materia. Mantendremos nuestro interés en colaborar con las instancias colegisladoras una vez que se renueve la discusión del proyecto de ley en cuestión”. Haroldo Brito, presidente de la Corte Suprema de Justicia, Cuenta Pública 2018 (disponible en: http://static.elmercurio.com/Documentos/ Legal/2018/03/01/20180301224131.pdf).
} 
vamente territorios normativos otrora de dominio de la prueba tasada. La conquista ha sido en algunos casos parcial (referida a ciertos procedimientos y a ciertos medios de prueba); en otros casos general. Es precisamente de tres de estas situaciones generales de las que trataremos en este artículo: la sana crítica como régimen general en materia penal; laboral y de familia.

La técnica legislativa empleada en las tres materias precedentes, sin embargo, ha generado algunas dudas respecto a la naturaleza y características del sistema. Estas dudas irradian sobre un conjunto de elementos propios de la fase probatoria judicial o conexos a ella que, analizados de forma comparativa, ponen en tela de juicio la unidad del régimen. En otras palabras, aunque se mantiene en materia penal, laboral y de familia una nomenclatura común (incluso una caracterización canónica compartida: los principios de la lógica, las máximas de la experiencia y los conocimientos científicamente afianzados), la forma en que legislativamente se ha implementado la sana crítica no resulta ser siempre coincidente; cuestión que lleva a la pregunta sobre si realmente todos los actores del sistema, por lo menos en los tres órdenes señalados, entienden lo mismo cuando se refieren a la sana crítica como régimen de ponderación general de la prueba judicial.

Para demostrar lo que venimos diciendo, en lo que sigue de estas páginas abordaremos la recepción normativa del régimen de ponderación denominado de la sana crítica. Centraremos nuestro estudio en los regímenes generales de ponderación conforme a la sana crítica, en especial los del derecho penal, del derecho laboral y del derecho de familia, para mostrar que, más allá de una nomenclatura de base compartida (un mismo término), existen una serie de diferencias normativas que, eventualmente, pueden modelar el concepto de forma diversa.

\section{RECEPCIÓN NORMATIVA DE LA IDEA DE SANA CRÍTICA}

En los últimos años se han dictado un conjunto de leyes que han consagrado con mayor o menor intensidad el sistema de la sana crítica en materia probatoria judicial. En algunos casos, como lo adelantábamos unas líneas más arriba, se ha tratado de disposiciones aisladas que funcionan como cláusulas de excepción dentro de un régimen general de prueba tasado. Es lo que se observa, por ejemplo, en el artículo 425 del Código de Procedimiento Civil; los artículos 543, 825 y 1206 numeral $4^{\circ}$ del Código de Comercio; el artículo 5 de la Ley 19.885, sobre donaciones y beneficios tributarios; el artículo 16 de la Ley 19.039, sobre propiedad industrial; el artículo 51 de la Ley 19.496, sobre protección al consumidor, referido a materias de intereses difusos o colectivos, y el artículo 33 de la Ley 19.537 sobre copropiedad inmobiliaria. 
En otros casos el legislador ha optado por introducir una cláusula general en favor de la sana crítica. En tal dirección avanzan, por ejemplo, las leyes números 18.287 (sobre procedimiento ante los Juzgados de Policía Local); 19.696 (Código Procesal Penal), 19.947 (Nueva Ley de Matrimonio Civil), 19.968 (Ley sobre Tribunales de Familia), 20.073 (Ley de Quiebras y Convenios Concursales), 20.087 y 20.260 (Sobre el procedimiento laboral), 20.316 (sobre Donaciones y Beneficios Tributarios), 20.322 (Ley sobre Fortalecimiento y Perfeccionamiento régimen Tributario y Aduanero), 20.600 (Tribunales ambientales) y 20.609 (sobre la no discriminación arbitraria).

La enunciación precedente no es taxativa, pero sí refleja de alguna manera la forma en que la sana crítica, como sistema de valoración de la prueba, se ha abierto paso en nuestro ordenamiento jurídico. Ahora bien, de las disposiciones precedentes a nosotros nos interesan sólo la ley 19.696, las leyes 20.087 y 20.260, y la ley 19.968. Es decir, aquellos cuerpos normativos que consagran como sistema general de ponderación de la prueba judicial la sana crítica en materia penal, laboral y de familia.

Cuando se atiende a estos cuerpos normativos se advierten dos cosas. La primera es una nomenclatura común, la segunda, un tanto más desconcertante, es que semántica y normativamente aquella nomenclatura no siempre expresa unas mismas ideas.

Veamos esto un poco más de cerca. El artículo 297 de la ley 19.696 dispone que "los tribunales apreciarán la prueba con libertad, pero no podrán contradecir los principios de la lógica, las máximas de la experiencia y los conocimientos científicamente afianzados. El tribunal deberá hacerse cargo en su fundamentación de toda la prueba producida, incluso de aquélla que hubiere desestimado, indicando en tal caso las razones que hubiere tenido en cuenta para hacerlo. La valoración de la prueba en la sentencia requerirá el señalamiento del o de los medios de prueba mediante los cuales se dieren por acreditados cada uno de los hechos y circunstancias que se dieren por probados. Esta fundamentación deberá permitir la reproducción del razonamiento utilizado para alcanzar las conclusiones a que llegare la sentencia”.

Por su parte el artículo 456 de la ley 20.087 establece que "el tribunal apreciará la prueba conforme a las reglas de la sana crítica. Al hacerlo, el tribunal deberá expresar las razones jurídicas y las simplemente lógicas, científicas, técnicas o de experiencia, en cuya virtud les asigne valor o las desestime. En general, tomará en especial consideración la multiplicidad, gravedad, precisión, concordancia y conexión de las pruebas o antecedentes del proceso que utilice, de manera que el examen conduzca lógicamente a la conclusión que convence al sentenciador". 
Finalmente, el artículo 32 de la ley 19.968 dispone que "los jueces apreciarán la prueba de acuerdo a las reglas de la sana crítica. En consecuencia, no podrán contradecir los principios de la lógica, las máximas de la experiencia y los conocimientos científicamente afianzados. La sentencia deberá hacerse cargo en su fundamentación de toda la prueba rendida, incluso de aquella que hubiere desestimado, indicando en tal caso las razones tenidas en cuenta para hacerlo. La valoración de la prueba en la sentencia requerirá el señalamiento de los medios de prueba mediante los cuales se dieren por acreditados cada uno de los hechos, de modo de contener el razonamiento utilizado para alcanzar las conclusiones a que llegare la sentencia".

Como se observa, el mínimo común denominador de las disposiciones precedentes es la apelación a términos usualmente asociados a la idea de sana crítica: los principios de la lógica, las máximas de la experiencia y los conocimientos científicamente afianzados. Sin embargo, una lectura atenta de los artículos revela cierta diferencia semántica. En tal sentido, recientemente Flavia Carbonell ha hecho notar con razón que de la lectura del artículo 297 del CPP es posible colegir, por lo pronto dos cosas: que existe una remisión a elementos "extrajurídicos" y que pesa, al parecer, sobre el órgano decisor una suerte de obligación de expresar estos criterios (y no meramente una prohibición de traspasar los límites de la sana crítica). Otro tanto acontece con el artículo 456 de la legislación laboral, en cuanto a la multiplicidad, gravedad, precisión y concordancia exigida para la valuación de la prueba, sobre las cuales Carbonell pregunta: ¿son consideraciones obligatorias que el juez debe tener en cuenta a propósito del uso de cada una de estas reglas? ¿O son, más bien, estándares para construir o evaluar la cadena de enunciados fácticos que desemboca en la formulación de la premisa fáctica o probandum final? Pareciese ser que se trata de nuevos criterios generales de racionalidad que recuerdan al juez que debe explicitar las razones de su decisión en una cadena coherente de enunciados a partir de la prueba que conste en el proceso".

A los comentarios de Carbonell hay que sumar aún otras consideraciones. De la lectura de las normas precedentes no es posible dilucidar epistémicamente si la sana crítica constituye una suerte de estándar probatorio (criterio con el cual se evalúa la corrección de la valuación de la prueba) o la forma misma que ha de asumir el razonamiento de ponderación. En efecto, un razonamiento puede ser bastante ilógico o contrafáctico y sin

${ }^{2}$ Carbonell, Flavia, Sana critica y razonamiento judicial, en Benfeld, Johann y Larroucau, Jorge (Eds.), La Sana Crítica Bajo sospecha (Valparaíso, Ediciones Universitarias de Valparaíso, 2018), pp. 39-40. 
embargo arribar a conclusiones lógicas y empíricamente consistentes. De modo tal que alguien podría sostener que todo testigo dice la verdad, Juan vende fruta; el testigo Juan dice la verdad. El entimema Todo M es S; todo $\mathrm{P}$ es $\mathrm{S}$, sigue siendo lógico sin perjuicio de que la premisa menor Juan vende fruta no forma parte del razonamiento. La diferencia es importante toda vez que los márgenes de discrecionalidad varían significativamente dependiendo de si se entiende a la sana crítica como un criterio independiente de validación de la ponderación probatoria, que es lo que ocurre en el artículo 297 del Código Procesal Penal al indicar que la valoración de la prueba será libre, pero no podrá contradecir los principios de la lógica, las máximas de la experiencia y los conocimientos científicamente afianzados. $\mathrm{O}$, por el contrario, si se entiende que la sana crítica es una condición del razonamiento probatorio en su conjunto, más allá de las conclusiones, cuestión que se puede colegir de los artículos 456 y 32 ya comentados.

Más interesante aún es la declaración que efectúa el artículo 456 del Código del Trabajo al señalar que fallar conforme a la sana crítica supone, entre otras cosas, por parte del tribunal el deber de "expresar las razones jurídicas y las simplemente lógicas, científicas, técnicas o de experiencia, en cuya virtud les asigne valor o las desestime”. De las tres disposiciones esta es la única que incluye como elemento de la sana crítica un aspecto normativo jurídico, aunque no precisa del todo cómo este elemento se puede tornar operativo dentro de un razonamiento probatorio ${ }^{3}$.

A estas consideraciones, desgraciadamente, no se les ha prestado toda la atención que merecen. Y esto, a su vez, ha impedido advertir las diferencias que luego es posible hallar en dichas materias. La explicación de esta situación, nos parece, hay que buscarla más allá de los confines normativos (como efectivamente hoy se regula el régimen de ponderación). Especialmente en la terminología y comprensión tradicional que la doctrina tiene sobre la sana crítica.

${ }^{3}$ En este orden de cosas, la doctrina nacional, nos parece, no ha reparado con la precisión científica requerida en la forma en que las disposiciones y principios de derecho sustantivo alteran las exigencias de la sana crítica. En otras palabras, no es lo mismo apreciar libremente la prueba en sede criminal (por ejemplo, bajo la idea de presunción de inocencia) que en sede labora (por ejemplo, bajo la idea del principio pro-trabajador). Esto que podría denominarse la cuestión de la modulación de la sana crítica, al igual que otros tantos problemas asociados a ella, no han recibido la atención que merece. En esta dirección véase Arellano, Pablo y Benfeld, Johann, Reflexiones sobre el principio de protección al trabajador y su influencia en el ámbito sustantivo y procesal del derecho laboral en Revista Chilena de Derecho y Tecnología vol. 6, no 2 (2107), pp. 12-21. 
Una rápida visita a los textos doctrinales (y también jurisprudenciales) que tratan sobre la sana crítica pone inmediatamente de manifiesto una terminología común. La sana crítica es entendida como un régimen de ponderación de la prueba judicial de naturaleza libre, que se caracteriza por una cierta exigencia de racionalidad, garantizada por la sujeción de la operación de valoración a los principios de la lógica, a las máximas de la experiencia y a los conocimientos científicamente afianzados.

Estas ideas, a su vez, traducen las aportaciones que sobre el particular hiciera Couture. Fue Couture quien definió, en nuestro horizonte próximo, la sana crítica como un sistema que "configura una categoría intermedia entre la prueba legal y la libre convicción. Sin la excesiva rigidez de la primera y sin la excesiva incertidumbre de la última, configura una feliz fórmula, elogiada alguna vez por la doctrina, de regular la actividad intelectual del juez frente a la prueba" ${ }^{4}$. Fue también Couture el que asoció expresamente el término con los principios de la lógica ("las reglas de la sana crítica consisten en su sentido formal en una operación lógica"s) y las máximas de la experiencia ("la sana crítica es, además de lógica, la correcta apreciación de ciertas proposiciones de experiencia de que todo hombre se sirve en la vida") ${ }^{6}$.

${ }^{4}$ Couture, Eduardo, Fundamentos del Derecho Procesal Civil (3a edición, Buenos Aires, Roque de Palma Editor, 1958), p. 270.

${ }^{5}$ Couture, cit. (n. 4), p. 271.

${ }^{6}$ Couture, cit. (n. 4), p. 272. Nominalmente los autores nacionales no han hecho otra cosa que repetir, con algunos matices, estas mismas ideas. Véase a este respecto Cerda San Martín, Rodrigo, Valoración de la prueba. Sana crítica, (Santiago, Librotecnia, 2008); LASO CORDERO, Jaime, Lógica y sana crítica en Revista Chilena de Derecho vol. 36, n. ${ }^{\circ}$ (2009), pp. 143-164; Lepín Molina, Cristián, Breve estudio sobre la sana crítica, en Gaceta Jurídica n. 319 (2007), pp. 7-13; LOPEZ Díaz, Carlos, Apreciación de la prueba por la sana crítica y procedencia del recurso de casación en el fondo en los procesos ante los tribunales de familia, en Gaceta Jurídica n. ${ }^{\circ}$ 294 (2004), pp. 22-27; Maturana Baeza, Javier, Sana crítica (Santiago, Thomson Reuters, 2014). En un registro un tanto diverso y explorando posibilidades narrativas que vayan más allá de los límites de la teoría cognoscitivista, es posible encontrar los trabajos de Coloma y Agüero. Véase, Coloma Correa, Rodrigo, La caída del argumento de autoridad y el ascenso de la sana crítica, en Revista de Derecho de Valdivia vol. 25, n. ${ }^{\circ} 2$ (2012), pp. 207-228; Coloma Correa, Rodrigo, Realmente importa la sana crítica, en Revista Chilena de Derecho vol. 39, no 3 (2012), pp. 753-781; Coloma, Rodrigo y Agüero, Claudio, Fragmento de un imaginario judicial de la sana critica, en Ius et Praxis 20, no 2 (2014), pp. 375-414. 
Sin embargo, sería un error pensar que la doctrina sólo ha bebido de esta fuente. De hecho, de Couture y sus ideas muy probablemente al día de hoy solo queda una nomenclatura, unos términos comunes y compartidos, pero poco más.

Para entender la discusión actual en torno a la sana crítica, como sistema de libre valoración de la prueba judicial, hay que mirar necesariamente el influjo que sobre ella ha ejercido la llamada tradición racionalista de la prueba $^{7}$, tanto en su vertiente anglosajona como continental.

En el contexto anglosajón, Anderson, Schum y Twinning han definido los términos de la discusión limitando el derecho probatorio a la valoración de los hechos desde una perspectiva empírica (con los métodos y estrategias propias de la ciencia moderna), cuyo objeto consiste en la averiguación de la verdad. De tal suerte que "el principio central de la tradición racionalista es que el objetivo primario del Derecho adjetivo (o procesal) consiste en lograr la 'rectitud de la decisión' en la adjudicación, es decir, la aplicación correcta del Derecho a los hechos probados como verdaderos"8. De esta idea se sigue también una cierta caracterización de la tradición, de forma tal que en ella, desde la perspectiva precedente, se asume como cierto que el conocimiento de los hechos pasados es posible; que el establecimiento de la verdad de los hechos (dentro de un proceso) es la condición necesaria para la justicia del caso particular; que existe una comunión necesaria y racional entre la verdad de los hechos y la decisión justa (en el derecho vigente); que a falta de juicios absolutos en materia de hechos a probar, ha de

${ }^{7}$ Esta tradición racionalista hunde sus orígenes, entre otros, en el pensamiento de Bentham. Para él, desde una perspectiva utilitarista (teoría comprehensiva y agregativa) y epistemológicamente empírica (los hechos como punto de anclaje científico), la prueba judicial constituye prácticamente el núcleo de todo proceso judicial. Pues, "cuando un particular se dirige a un juez, es para reclamarle una decisión, que no puede sino referirse a un punto de hecho o a un punto derecho. A un punto de hecho, cuando se trata de saber si estima que el hecho que se le somete es verdadero o no; en ese caso la decisión no puede tener otra base que la prueba". Y luego, "así, pues, el arte del proceso no es esencialmente otra cosa que el arte de administrar las pruebas". Y para concluir, "la exclusión de toda prueba sería la exclusión de toda justicia”. Bentham, Jeremy, Tratado de las Pruebas Judiciales (traducción C.M.V., Buenos Aires, Valletta Ediciones, 2008), pp. 12, 13, 400. Sin embargo, no fue sino hasta el advenimiento de la New Evidence Scholarship en que la teoría racional de la prueba judicial adquirió sus contornos actuales. Véase LEMPERT, Richard, The New Evidence Scholarship: Analyzing the Process of Proof, en Boston University Law Review, no 66 (1986), pp. 439-477.

${ }^{8}$ Anderson, Terence, Schum, David y Twining, William, Análisis de prueba (traducción de Daniela Accatino, Claudio Agüero, Federico Arena, Flavia Carbonell, Rodrigo Coloma, Juan Pablo Fassnidge y Jorge Larroucau, Madrid, Marcial Pons, 2015 [2005]), p. 116. 
recurrirse al cálculo de probabilidades; que el uso instrumental del cálculo de probabilidades debe ser realizado en términos racionales (justificados); que las probabilidades han de interpretarse siempre en términos de natural ocurrencia de los hechos (sentido común) y de acuerdo al estado actual de la ciencia; que en materia probatoria, la búsqueda de la verdad debe tener prioridad frente a otros fines del proceso (seguridad del Estado, el orden de las familias, la protección de garantías individuales, etcétera); que la evaluación de las reglas probatorias y de procedimiento probatorio han de juzgarse por su eficacia en la obtención de la verdad más que en otros criterios y valores disponibles en el sistema (celeridad, economía, etcétera); y que la psicología forense y la ciencia del procedimiento deben esforzarse en proveer a los operadores jurídicos (sobre todo al juez) métodos fiables para la búsqueda de la verdad de los hechos?.

La elaboración europeo continental de esta tradición ha estado a cargo, entre otros, de Michelle Taruffo en Italia y algunos de los teóricos de las llamadas escuelas de Girona y Alicante en España ${ }^{10}$.

Taruffo presenta su teoría de la prueba judicial desde dos perspectivas diferentes pero complementarias. En primer término, y desde un horizonte político institucional, conecta la teoría con los principios normativos de un Estado de Derecho (principio de sujeción a la ley y protección de garantías fundamentales). Desde esta perspectiva, el sistema probatorio constituye una garantía del debido proceso y éste, a la vez, funciona como seguridad de los derechos fundamentales igualmente distribuidos entre los ciudadanos (característica propia de los regímenes democráticos). En segundo lugar, como salvaguardia epistemológica de la "decisión correcta", la teoría se construye sobre bases epistémico-empíricas cuyo propósito fundamental (aunque no exclusivo ni excluyente) es la averiguación de la verdad ${ }^{11}$.

En la misma dirección Jordi Ferrer hace notar que no es posible ga-

${ }^{9}$ Véase a este respecto, Twining, William, Rethinking Evidence. Exploratory Essays (2a edición, Cambridge, Cambridge University Press, 2006), p. 76.

${ }^{10}$ Aquí se imponen los nombres de Jordi Ferrer, Carmen Vásquez, Marina Gascón, Daniel Gonzáles, entre otros.

${ }^{11}$ En palabras del propio Taruffo, "según la opinión dominante, el derecho a presentar todas las pruebas relevantes es parte esencial de las garantías generales sobre la protección judicial de los derechos y del derecho de defensa, pues la oportunidad de probar los hechos que apoyan las pretensiones de una de las partes es condición necesaria de la efectividad de tales garantías" (TAruffo, Michele, La Prueba, trad. L. Manríquez, J. Ferrer, Madrid, Marcial Pons, 2008), p. 56. Y en otro lugar, "por consiguiente, el juez es realmente imparcial en tanto busca de forma objetiva la verdad de los hechos, haciendo de ella el verdadero y exclusivo fundamento racional de la decisión". Taruffo, Michele, Simplemente la verdad (trad. Daniela Accatino, Madrid, Marcial Pons, 2010), p. 138. 
rantizar la justicia y seguridad jurídica si no es dable, también, probar la verdad de los hechos que funcionan como condición para el surgimiento de consecuencias normativas (supuesto jurídico) en un Estado de Derecho. $\mathrm{Y}$, siguiendo a Taruffo, afirma que el fin propio de la prueba judicial es la averiguación de la verdad (como correspondencia, aunque desde una perspectiva realista-crítica). Eso sí, en un grado de sofisticación mayor, propone un ejercicio de desagregación conceptual que permite analizar la fase probatoria en su conjunto desde la perspectiva de tres espacios estancos: recolección del material probatorio, valoración de la evidencia y aplicación del estándar de prueba. Para que el modelo prospere, con todo, tiene que centrar su atención sólo en el segundo momento (valoración de la prueba) ${ }^{12}$.

En resumen, lo que caracteriza a la tradición racionalista en sus dos vertientes (common law y civil law) es que ella centra su atención en el valor epistemológico de la verdad como fin preeminente de la prueba judicial. Para realizar su cometido, se supedita a los métodos y principios propios de las ciencias empíricas cuestión que, por lo mismo, la deja inscrita en un registro propio de la racionalidad empírica que, en su versión actual, también se condice con una concepción realista no ingenua de la realidad (la verdad es una correspondencia entre enunciados fácticos y hechos efectivamente acaecidos en las coordenadas espacio-temporales).

Son precisamente estos compromisos teóricos, y no solo la nomenclatu-

${ }^{12}$ Así, dentro de la tradición racionalista de la prueba no existe inconveniente alguno en eliminar, en tanto las particularidades de la actividad lo permitan, todas las barreras que separan la averiguación de la verdad dentro de un proceso judicial de aquélla propia de las ciencias (naturales o sociales). Así, desagregando analíticamente las fases de etapa probatoria, la fase de valoración de la prueba judicial es comparada con un experimento clínico y el tribunal con un laboratorio. En la etapa de valoración no caben, pues, consideraciones de naturaleza extra epistémicas, las cuales sólo entrarán en un momento anterior o posterior de admisión o decisión sobre la prueba rendida en autos. En tal sentido, Jordi Ferrer ha señalado que, a propósito de los diversos momentos de la fase probatoria (conformación de los elementos de juicio probatorio; valoración de los elementos de juicio; adopción de una decisión con ocasión de los elementos antes señalados), existen efectivamente diferentes valores en competencia, pero que en la fase de valoración de la prueba "reina sin competencia el valor de la averiguación de la verdad" (FERRER, Jordi, La valoración racional de la prueba (Madrid, Marcial Pons, 2007), p. 47. Vid. También Ferrer, Jordi, Motivación y racionalidad de la prueba (Lima, Ed. Jurídica Grijley, 2016), pp. 147-171. En la misma dirección Gascón afirma que "en un modelo cognoscitivista las únicas valoraciones legales admisibles serían aquellas que constituyan un reflejo de los medios de prueba científicamente contrastados y de su fiabilidad prácticamente absoluta. Simétricamente la 'libre convicción', al permitirle al juzgador desligarse de cualquier valoración preconstituida, propicia la averiguación de la verdad”. GASCÓN, Marina, Los Hechos en el Derecho (Madrid, Marcial Pons, 2010), p. 141. 
ra, los que han de ser usados como insumos para la adecuada comprensión del trabajo dogmático actual sobre la sana crítica como sistema de libre valoración de la prueba ${ }^{13}$.

Esta aproximación a la sana crítica (desde la tradición racionalista) ha tenido, a nuestro juicio, la virtud de conectar de forma razonable las exigencias de justificación racional de las decisiones judiciales con los fundamentos del estado de derecho (igualdad ante la ley y debido proceso) y con la idea de democracia (y su exigencia de justicia), mediante la promoción del establecimiento de ciertos baremos de racionalidad teóricopráctica en las fundamentaciones de las sentencias judiciales. También ha tenido, desde el punto de vista epistemológico, el mérito de clarificar metodológicamente, en un proceso de desagregación conceptual, cuáles elementos del extrarradio jurídico (epistemológicamente hablando) han de servir como recursos para la averiguación de la verdad de los hechos en un proceso judicial ${ }^{14}$.

Sin embargo, especialmente este último aspecto (entronización de los dispositivos epistemológicos) también ha contribuido a una falta de comprensión del sistema de ponderación de la prueba en los diferentes contextos normativos. Pues la unificación de la teoría desde una perspectiva preeminentemente epistemológica la obliga a asumir una actitud ascética respecto de los otros fines y valores asociados al proceso judicial (que muy probablemente permean la fase probatoria en su conjunto), convirtiéndola en una suerte de catre de Procusto que no conforme con la comprensión de las cos a $\mathrm{s}$ com o s o n las recorta a su imagen y semejanza para adecuarlas a una teoría que en el fondo pretende indicarnos cómo las cosas $\mathrm{d}$ e b e n $\mathrm{s}$ e r.

Este último aspecto fuerza a la teoría racionalista o cognoscitivista a realizar una especial clasificación de las normas probatorias en orden a su alineación o no con la teoría, es decir, si las normas con incidencia probatoria permiten o no la libertad del sentenciador a fin de realizar una valuación racional de la prueba o, por el contrario, la restringen. En este contexto, y ahora mirando el cuadro general y no solo al elemento analíticamente desagregado de la "valoración de la prueba", las llamadas leyes reguladoras de la prueba (en sentido amplio todas aquellas que inciden

${ }^{13}$ En nuestro país, este ascendiente conceptual se puede advertir con bastante claridad en los trabajos de D. Accatino. Sobre el particular véase especialmente: Accatino, Daniela, Legal evidence theory: are we all "rationalists" now?, en Revus, $\mathrm{n}^{\circ}$ 40 (2020), pp. 85-101.

${ }^{14}$ Coloma, Rodrigo y Agüero, Claudio, Lógica, ciencia y experiencia en la valoración de la prueba, en Revista Chilena de Derecho vol. 41, no 2 (2014), pp. 673703. 
en la fase probatoria) son clasificadas conforme a su aptitud o ineptitud para averiguar libremente la verdad. Así algunos teóricos hablan de reglas reguladoras de la prueba de contenido contra-epistemológico y otras de carácter epistemológico y aún otras simplemente neutras. Asimismo, se usa la expresión de "reglas coadyuvantes de la búsqueda de la verdad" y otras contrarias a la misma, a propósito de las situaciones referidas a la formalización de las reglas probatorias (prueba tasada), a la limitación temporal de los procesos judiciales; a las reglas de exclusión probatoria; a las presunciones de derecho y otras de similar naturaleza. En este registro, puesto que la teoría racionalista entiende que el principal objetivo del derecho procesal es la averiguación de la verdad, se llega a afirmar que las normas contra-epistemológicas son desviaciones "patológicas" de los fines mismos del proceso judicial. "Se trata, por regla general, de reglas que, orientándose primariamente a asegurar la tutela de determinados valores extraprocesales que se consideran relevantes, hacen prevalecer éstos frente a las exigencias procesales de averiguación de la verdad"15.

El argumento persuasivo en el cual funcionan las objeciones a las reglas probatorias contra-epistémicas (reglas de exclusión, por ejemplo) ha sido bien expresado por Taruffo: "según la opinión dominante, el derecho a presentar todas las pruebas relevantes es parte esencial de las garantías generales sobre la protección judicial de los derechos y del derecho de defensa, pues la oportunidad de probar los hechos que apoyan las pretensiones de una de las partes es condición necesaria de la efectividad de tales garantías" ${ }^{16}$. Cuestión que permite, en este contexto como condición sine qua non, la realización de la justicia. En tal sentido, insisten los cognoscitivistas en que toda limitación a la información produce algún grado de perjuicio. Por lo mismo, lejos de preguntarse por el eventual valor que dichas reglas (contra-epistemológicas o simplemente neutras) podrían tener para el derecho probatorio se apresuran a sostener que las disposiciones de naturaleza contra epistémica generan efectos perjudiciales que al final pesan más que el valor probatorio legítimo de la prueba presentada, cuestión que obliga a los operadores jurídicos a elaborar argumentos persuasivos para desactivarlas ${ }^{17}$. Así las cosas, lo único que cabe respecto a este tipo de reglas es lograr desarrollar argumentos con una fuerza persuasiva suficiente como para lograr en el caso en cuestión su desactivación normativa, con prescindencia del valor jurídico-político que éstas afirmen.

\footnotetext{
${ }^{15}$ GASCÓN, cit. (n. 12), pp. 118-119.

${ }^{16}$ Taruffo, La prueba, cit. (11), p. 56.

${ }^{17}$ Anderson, Schum \& Twining, cit. (n. 8), p. 302.
} 


\section{EL DISEÑO NORMATIVO CON INJERENCIA PROBATORIA EN LOS PROCEDIMIENTOS PENAL, LABORAL Y DE FAMILIA}

Para los teóricos de la prueba, como venimos diciendo, no es ningún misterio que el diseño normativo de los procedimientos ejerce, por lo menos, alguna influencia en la ponderación de la prueba judicial. Larry Laudan, por ejemplo, ha señalado (muy a su pesar) que en la medida que ciertas consideraciones meta epistemológicas estén presentes en un proceso judicial es imposible garantizar el acceso a la verdad de los hechos y a la justicia del caso. Específicamente él está pensando en lo que denomina "derechos que (al menos en su interpretación ortodoxa) constituyen serios obstáculos, algunas veces incluso graves, para llegar a veredictos correctos" ${ }^{18}$. De esta afirmación se siguen por lo pronto dos cosas: la primera es que la corrección de los veredictos judiciales depende de la averiguación de la verdad de los hechos; y la segunda, consiste en que hay "derechos" que tendencialmente producen fallos incorrectos. No nos vamos a detener en este punto, pero ¿̇acaso no es precisamente esta constatación la que debería haberlo llevado hacia otra conclusión?: en derecho la rectitud y corrección del fallo no siempre depende de la verdad de los hechos.

Laudan, por cierto, detiene su análisis en ciertas disposiciones probatorias propias del procedimiento criminal. Taruffo, sin embargo, va más lejos aún y, desde una perspectiva epistemológico-normativa no se limita a criticar ciertas disposiciones particulares sino el diseño y orientación de procedimientos completos. En tal dirección el denominado proceso adversarial (también el dispositivo) es presentado como el paradigma del error. "De cuanto se ha dicho hasta ahora, resulta, en cambio, evidente que, tanto para la ideología adversarial como para la concepción del proceso inspirada en el principio dispositivo (en cualquiera de sus diversas versiones), la verdad de los hechos es por completo irrelevante. Aún más: la verdad se presenta como un fin que las partes no pretenden perseguir y, por tanto, cualquier actividad encaminada en esa dirección está destinada a parecer inútil derroche de tiempo y recursos" 19 .

En ambos casos, con todo, resulta interesante el reconocimiento expreso

${ }^{18}$ LaUdan, Larry, Verdad, error y proceso penal (trad. Carmen Vásquez y Edgar Aguilera, Madrid, 2013), p. 298.

${ }^{19}$ TARuffo, Simplemente la verdad, cit. (n. 11), p. 131. Es imposible no detenerse un momento en las afirmaciones de Taruffo. Del hecho de que en los referidos procedimientos (adversaria y dispositivo) muchas veces están en juego "otros" valores de naturaleza no epistemológica, él deriva sin más que en ellos la verdad no tiene ninguna importancia. A nosotros nos parece que, por el contrario, en dichos procedimientos la verdad importa, pero no necesariamente es relevante para la 
que realizan Laudan y Taruffo de los elementos meta-epistémicos (sean normas particulares o procedimientos generales que consagran disposiciones contra epistémicas). Pero si las cosas en la realidad son así, para comprender el fenómeno probatorio judicial ¿no será necesario tener en consideración los aspectos normativos de diseño y contenido en los cuales realmente la prueba judicial se desenvuelve?

En este punto surge, entonces, la cuestión de determinar qué elementos son relevantes para comprender las particularidades de la prueba judicial.

Dejando de lado la existencia de principios procesales compartidos en los tres procedimientos que someramente y de forma muy esquemática veremos (el principio de contradicción; el de inmediación; el de oralidad y el de publicidad) y sin que se trate de una enumeración taxativa, exhaustiva o siquiera correcta, nos parece que es posible distinguir dos tipos de regulación sobre el particular. En primer lugar, es posible encontrar cinco elementos de naturaleza normativa estructural presentes en prácticamente todos los procedimientos judiciales que, nos parece, inciden de forma directa o indirecta en la fase probatoria y que, por lo mismo, inevitablemente la orientan (o si se prefiere, desde una perspectiva epistemológica de la teoría racionalista, la "contaminan"). Estos elementos son: la existencia de principios rectores de la especialidad (propios del derecho sustantivo criminal, laboral y de familia, en el caso que nos ocupa); normas reguladoras de la formación del material probatorio; normas sobre valoración de la prueba; reglas que determinan el estándar de prueba; normas sobre fundamentación de la sentencia judicial y disposiciones que regulan el régimen recursivo. De alguna forma, estos elementos se encuentran mutuamente imbricados en la práctica forense, aunque analíticamente pueden ser desagregados y considerados de forma independiente.

En segundo lugar, y desde una perspectiva operativa, hallamos disposiciones que regulan la manera en que se diligencia la prueba; las potestades materiales que el ordenamiento concede al juez y la posibilidad de decretar por él mismo pruebas de oficio; la composición del tribunal; la existencia de órganos asesores en la actividad de probatoria (consejo técnico); los conocimientos exigidos por el ordenamiento para el ejercicio de la actividad de valuación de la prueba a los jueces y, finalmente, el tiempo que disponen los órganos jurisdiccionales para emitir su fallo. Se trata, en consecuencia, de otros cinco elementos de naturaleza jurídico-institucional que también influyen en la prueba judicial.

Ahora bien, si la sana crítica es un sistema único de ponderación judicial,

corrección de un fallo, en la medida en que éste logre efectivamente una solución pacífica y satisfactoria para las partes. 
inmune al contexto normativo, los elementos enunciados en el párrafo precedente (diez en total) debiesen, por una parte, aparecer implementados de manera muy similar en los procedimientos criminal, laboral y de familia y, por otra, el diseño normativo no debiese impactar de manera determinante la fase de valoración de la prueba. Por el contrario, si es posible advertir a nivel normativo variaciones significativas en estos elementos que, además, influyen de manera considerable en la valoración de la prueba judicial, resulta que la aproximación meramente epistemológica a la sana crítica debe ser sometida a examen, a fin de lograr una adecuada comprensión de la misma.

Para lograr tener una visión general sobre lo que venimos diciendo, el siguiente cuadro comparativo sobre disposiciones que inciden en la prueba puede ser de gran utilidad.

$$
\begin{array}{cc}
\text { Derecho } & \text { Derecho del } \\
\text { Penal } & \text { Trabajo }
\end{array}
$$

\section{Derecho del Trabajo}

a) Principio sustantivo de la rama

\begin{abstract}
Presunción de inocencia (art. $4^{\circ} \mathrm{CPP}$; art. 8.2 de la Convención Americana de Derechos $\mathrm{Hu}-$ manos; art. $14.2 \mathrm{del}$ Pacto Internacional de Derechos Civiles y Políticos de $\mathrm{Na}$ ciones Unidas, art. $5^{\circ}$ inc ii, $\mathrm{CPRCH}$ (se encuentra incorporado al llamado bloque constitucional de garantías fundamentales).
\end{abstract}

Protección al trabajador (art. 19, no $16 \mathrm{CPRCH}$; arts. 425 y siguientes $^{20}$; art. 5 inc. ii $\mathrm{CPRCH}$.

\section{Derecho \\ de Familia}

\begin{abstract}
Igualdad en la relación marital y a contraer matrimonio (art. 2 y 3 Ley 19.947). Interés superior del niño, niña y adolencente (en particular art. 16 ley 19968 (LTF), y en general el Título III, Párrafo I de la Ley; art. 5 inc. ii $\mathrm{CPRCH}$; art. 3 inc. $1^{\circ}$ Convención sobre los Derechos del Niño 1989 y art. 3 de la Ley 19.947) ${ }^{21}$; protección a la parte más débil de la relación de familia (art. 3 Ley 19.947).
\end{abstract}

${ }^{20}$ Para un análisis detallado sobre las manifestaciones normativas del principio de protección al trabajador en el orden jurisdiccional, véase Gamonal, Sergio, El derecho procesal del trabajo, sus caracteres y el principio de igualdad por compensación, en Revista de Derecho Laboral y Seguridad Social (2015), vol. III, no 1, pp. 101 y siguientes. (89-119).

${ }^{21}$ Para un estudio sobre la evolución histórica del concepto normativo de "interés superior del niño" y su implementación en la legislación nacional, véase BAEZA, Gloria, El interés superior del niño: derecho de rango constitucional, su recepción en la 
b) Existencia No es adminsible. No está regulada. de prueba tasada

c) Presunciones

d) Convenciones probatorias

e) Exclusión de Art. 276 CPP. prueba

f) Potestades No tiene posibimateriales del juez en materia probatoria
Presunción de inocencia, art. $4^{\circ} \mathrm{CPP}$, en sentido favorable al imputado. En general, en contra, no se admiten; aunque existen algunas disposiciones sustantivas dudosas: art. 111 de la ley 18.250 (ley de transito).

Art. 275 CPP. lidad de solicitar aclarar dichos a testigos y peritos (art. 326 inciso tercero y art. 329 inciso cuarto).
En general no regulada.

No está regulado expresamente.

Art. 453 no 4 CT. Art. 31 LTF.

Posibilidad de interrogar a testigos (art. $454 \mathrm{~N}^{\circ} 6$ ).
Art. 57 LTF en relación con el Título XVII del Libro I del Código Civil (prueba del estado civil).

De aplicación conforme a las reglas generales Código de Procedimiento Civil, de acuerdo al art. 27 LTF.

Art. 30 LTF.

Prueba de oficio (art. 29 inciso tercero LTF); posibilidad de preguntar a las partes (art.51 inciso primero LTF); posibilidad de preguntar a testigos y peritos (art. 64 inciso tercero LTF). 
g) Asesoria No tiene. No tiene. especializada en la apreciación de la prueba

h) Orden en que se presenta la prueba

i) Composición del tribunal
Cada parte determinará el orden en que rendirá su prueba (art. 328 CPC).
Documental, confesional, testimonial y los otros medios ofrecidos, sin perjuicio el tribunal pueda modificar el orden por causa justificada. (art. 454 letra a, CT).

Unipersonal/Colegiado (art. 14 y 17 COT).
Consejo Técnico (art.5, auxiliares de la administración de justicia); practicada la prueba, el juez puede solicitar la opinión respecto de ella a un miembro del consejo técnico (art. $64 \mathrm{n}^{\circ} 6$ LTF).

Partes deciden el orden en que se presenta (art. 64 inciso primero LTF).

Unipersonal (con asesoría del Consejo Técnico). Habitualmente, además, en los procesos de familia es el mismo juez quien participa en la audiencia preparatoria como en la de juicio oral. Cuestión altamente inconveniente por los sesgos epistémicos (art. 3 LTF). 
j) Estándar de Prueba $^{22}$

k) Tiempo para dictar sentencia

l) Exigencia de fundamentar la apreciación que se ha realizado e los elementos de prueba

\section{m) Control} recursivo por inobservancia de las reglas de la sana crítica
Más allá de toda duda razonable (art.340 CPC); En materia de DDHH, preferencia de las buenas explicaciones no derrotadas ${ }^{23}$; para acciones civiles, prueba prevaleciente.

Concluida la deliberación privada de los jueces, como excepción la deliberación podrá tomar 24 horas. en casos complejos (art. 339 y 343 СРP).

Art. 297 incisos segundo y tercero; art. 342 letra c (contenido de la sentencia).
Prueba prevaleciente por adherencia (CC); en casos de procedimiento de tutela laboral, prueba indiciaria (art. 493CT); por el contrario, se exige prueba clara y convincente por parte del empleador.

Al término de la audiencia de juicio o dentro de décimo quinto día de realizada (art. 457 CT).
Prueba prevaleciente por adherencia (CC); especial indeterminación en la distribución de riesgos.
Inmediatamente concluido el debate, como excepción al día siguiente hábil si el juicio se hubiere prolongado por más de dos días (art. 65 LTF).

Art. $459 \mathrm{~N}^{\circ} 4$.

Art. 32 inciso primero y segundo (valoración de la prueba); El contenido de la sentencia exige hacerse cargo del análisis de la prueba, pero nada se dice de la SC (Art. $66 \mathrm{~N}^{\circ} 4 \mathrm{LTF}$ ).

Casación en la forma (art. 67 No6 letra b LTF).
Recurso de nulidad (art. 478 letra b).
Motivo absoluto de nulidad (art. 374 letra e).

${ }^{22}$ Hacemos presente que, en esta materia, salvo en el caso del Código Procesal Penal, no existe una regulación general o marco normativo explícito para los procedimientos laboral y de derecho de familia. Por esta razón supletoriamente se aplica la normativa del Código Civil que, a su vez, tampoco contempla un único criterio rector sobre el particular. Cuestión que se traduce en que doctrinalmente se afirma que el criterio es el de prueba prevalente, con especial atención al valor propio asignado al medio probatorio en forma particular y comparativa.

${ }^{23}$ Coloma Correa, Rodrigo, Estándares de prueba y juicios por violaciones a los Derechos Humanos, en Revista de Derecho vol. XXII, no 2 (2009), pp. 205-229. 
n) Conoci- $\quad$ No se exige. No se exige.
miento es-
pecial de los
jueces sobre
ciencias co-
adyuvantes
(episte-
mología,
psicología,
sociología,
etc.)

Como hemos dicho un poco más arriba, la teoría cognoscitivista de la prueba afirma que todas las reglas de contenido contra-epistemológico constituyen desviaciones (incluso para alguno, patológicas) de la búsqueda de la verdad en los procedimientos judiciales. Dentro de estas reglas se encuentran las disposiciones que formalizan normas de prueba; las que permiten convenciones probatorias; las normas que establecen presunciones de derecho; las que limitan temporalmente la resolución del proceso, impidiendo una consideración detallada de la prueba rendida en autos; las reglas que excluyen pruebas por haber sido éstas obtenidas con infracción de ley o vulneración de garantías constitucionales, entre otras.

Si observamos el cuadro precedente resulta claro que en los procedimientos ordinarios que esbozamos, dado su diseño actual, pueden ser calificados por la teoría cognoscitivista como procesos que adolece de ciertas patologías congénitas. Ello, simplemente si se atiende a las disposiciones contenidas en las letras A, B, C, D, E, I y K, que hemos consignado en el mismo. También en el cuadro es posible advertir algunas disposiciones de naturaleza epistémica: letras F, G, J, L y M. Por último, existen algunas normas que podríamos calificar de neutras epistémicamente hablando. Este es el caso de las letras $\mathrm{H}$ y $\mathrm{N}^{24}$.

La existencia del primer grupo de disposiciones (de contenido contra epistémico), en el procedimiento ordinario, puede dar lugar, según la teoría racionalista de la prueba, a un significativo aumento de obstáculos para la averiguación de la verdad. Pues, tras la opción por un sistema libre de ponderación, el legislador ha limitado la actuación judicial mediante el establecimiento de convenciones probatorias, reglas de exclusión, presunciones e incluso alguna prueba tasada. Además, la composición del tribunal

${ }^{24} \mathrm{No}$ es este el lugar para realizar un estudio comparativo de las leyes regulatorias de la prueba en cada uno de estos procedimientos, pero advierta el lector la disímil regulación de la materia; cuestión que, a nuestro juicio, por cierto, tiene incidencia en la valuación de la prueba. 
$y$, sobre todo, el tiempo que se le ha otorgado para dirimir el conflicto (inmediatamente concluida la audiencia de juicio), representa una nueva regla contra epistémica que en nada colaboración con la averiguación de la verdad de los hechos. Todo ello sin considerar la interpretación que los propios tribunales hacen de las disposiciones de contenido teóricamente "epistémico"25.

La comparación teórica realizada desde una perspectiva únicamente epistemológica, con todo, puede no dejar ver las sutilezas, complejidades y opciones normativas extra epistémicas. Y aunque no es posible realizar en este momento un estudio detallado de todos y cada uno de los elementos normativos que aparecen regulados en el cuadro comparativo de forma diversa en los procedimientos en estudio, sí puede resultar interesante ver cómo el diseño normativo particular de uno de estos procedimientos influye en la prueba de los hechos en un caso particular. En este sentido, la causa rol O-833-2016, seguida ante el Tribunal de letras del Trabajo de Valparaíso y caratulada como "Órdenes Abarca v/s Electricidad Gobante S.A", nos puede brindar un buen ejemplo de lo que Kant (por cierto, en otro contexto) ya intuía: "tal vez eso sea correcto en teoría, pero no sirve para la práctica" ${ }^{26}$.

\section{El caso “Órdenes v/s Gobante S.A.” COMO ejemplo de las INFLUENCIAS NORMATIVAS EN LA VALORACIÓN DE LA PRUEBA}

La cuestión a resolver en este caso era si determinados insultos proferidos por un trabajador en contra de su jefe directo podían servir de base para el despido justificado del mismo. Supuesto contemplado en el artículo $160 \mathrm{~N}^{\circ} 1$ letras c) y d) del Código del Trabajo ${ }^{27}$. Conforme a la prueba rendida en autos, efectivamente se pudo acreditar que el trabajador, que en al momento de los hechos se desempeñaba como chofer de la empresa,

${ }^{25}$ A modo ejemplar, véase: Fuentes Maureira, Claudio, La persistencia de la prueba legal en la judicatura de familia, en Revista de Derecho Coquimbo vol. 18, no 1 (2011), pp. 119-145.

${ }^{26}$ Vease, Kant, Emanuel, Teoría y Práctica (trad. Juan Palacios, Francisco Pérez y Roberto Rodríguez, 4a edición, Madrid, Tecnos, 2006).

${ }^{27}$ Conviene tener presente, a su vez, lo que prescribe este artículo. La norma en cuestión señala que "el contrato de trabajo termina sin derecho a indemnización alguna cuando el empleador le ponga término invocando una o más de las siguientes causales: 1.- Alguna de las conductas indebidas de carácter grave, debidamente comprobadas, que a continuación se señalan: c) Vias de hecho ejercidas por el trabajador en contra del empleador o de cualquier trabajador que se desempeñe en la misma empresa; d) Injurias proferidas por el trabajador al empleador". A su vez, la Real Academia de la Lengua Española define injuria como un "agravio, ultraje de obra o de palabra". 
profirió a viva voz y en contra de su jefe una expresión obscena. En la especie, que tanto su jefe como su pretendida autoridad tenían un valor, en la mejor de las interpretaciones posibles, equivalente a una seta silvestre.

Lo interesante del caso es que este hecho (bruto ${ }^{28}$ ) y el conjunto de proposiciones fácticas que lo afirman se dio por acreditado en la especie. Para ello se estuvo a la declaración de partes y testigos, los cuales con ciertos matices coincidieron en el hecho puntual de que el trabajador habría dirigido la obscenidad, por lo menos, en dirección de su jefe (aunque no necesariamente a él). Sin embargo, como veremos a continuación, en el caso lo relevante no es la prueba del hecho (bruto), sino la valoración de la prueba (la verificación de alguno de los supuestos contenidos en el artículo 160).

En efecto, el Tribunal del Trabajo sostuvo en su considerando séptimo que "finalmente los dos testigos de la demandada, Valdés y Rivadeneira, que dicen haber estado presentes y por tanto escucharon cuando el actor dijo "vale callampa", añaden que esto no se lo dijo directamente, no le miraba a la cara, que se habia dado vuelta y caminaba hacia la camioneta. Luego, al preguntarle Rivadeneira porqué decía eso, no hubo conflicto ni otras palabras ofensivas. Lo que lleva a concluir que efectivamente el actor estaba estresado, como señaló José Manuel Ramos y que la frase tantas veces repetida "vale callampa" no fue dicha con la intención de ofender o insultar directamente a su jefe, sino que fue usada para liberar su estrés al sentirse presionado, en términos de una exclamación o interjección, que se ha hecho muy popular en nuestro pais. Sobre todo, si se considera que todos los declarantes señalan que habia buen clima laboral, que no habia insultos, aunque a veces se daban discusiones, sin conflicto y que, en ese medio se desenvolvió el actor durante 12 años".

Por último, el tribunal en su considerando octavo dispone que, "por lo expuesto, se concluye que el despido del actor jue injustificado e indebido $y$, por tanto, le corresponde se le paguen las indemnizaciones que impetró".

Como era de esperar, la parte demandada interpuso dentro de plazo y conforme a derecho un recurso de nulidad fundado precisamente en la infracción de las normas sobre apreciación de la prueba de acuerdo a las reglas de la sana crítica (artículo 478, letra b del código de la rama). Y, como era predecible también, perdió el recurso.

La Corte de Apelaciones de Valparaíso, desestimó el recurso de nulidad y en un extenso considerando tercero señaló que "que no cabe

${ }^{28}$ Uso el término "hecho bruto" en un sentido técnico, tal como aparece en Gertrude Anscombe (Anscombe, G., On Brute Facts, en Analysis vol 18, no 3 (1958), p. 73), como opuesto a un "hecho con trasfondo institucional". Y este uso, como se verá más adelante, es determinante para comprender el error del tribunal a quo y ad quem desde una perspectiva meramente epistémica del análisis del lenguaje. 
aceptar el planteamiento del recurso de nulidad, puesto que en los fundamentos transcritos del fallo cuestionado no se observa la denuncia de vulneración al principio de contradicción ni a las máximas de experiencia en los términos que se ha acusado, puesto que conforme a la valoración de la prueba testimonial que hizo el juzgador se determinó que si bien el actor señaló la expresión 'vale callampa' ésta no pudo ser calificada como injuria ni vía de hecho, dado que en el contexto que fue manifestada aparece que no se trató de una acción que implicara una afrenta o agravio, esto es, el dicho del trabajador no ofendió la honra, ni tuvo por objeto desacreditar o menospreciar a su empleador, en el caso, representado por su jefe directo. Para ello el tribunal tuvo presente que la expresión fue dicha por el trabajador cuando caminaba hacia una camioneta sin mirar a su jefe, que no se sumaron otras expresiones y que la ejecución de las labores se desarrolló de manera normal. En ese contexto, no puede aseverarse que se falte a las reglas de las máximas de experiencia, pues en esa situación, es claro que la expresión no puede configurar una injuria, toda vez que no se vio afectada en modo alguno la honra, esto es, ni desde una perspectiva objetiva-el prestigio del empleador en su poder de dirección o disciplina-ni subjetiva -su autoestima-.".

Ahora bien, intentar explicar de manera satisfactoria el razonamiento probatorio en esta causa desde la perspectiva de la teoría racionalista es posible, aunque probablemente nada fácil. Pues si de la verdad de los hechos se trata, las obscenidades dirigidas por el trabajador a su jefe directo no se encuentran controvertidas. Que por cierto no ha de haber sido una situación menor y sin importancia lo demuestra el despido mismo realizado por el empleador. Y, sin embargo, ni el tribunal de instancia, ni la Corte de Apelaciones, conociendo del recurso de nulidad laboral, han considerado relevante la verdad de la proposición fáctica referida al hecho (bruto), sino que han valorado la prueba del mismo desde un horizonte exorbitante a la verdad del factum, calificándolo como una expresión de desahogo. Esta valoración de la prueba, sin embargo, y contrario a lo que pudiera afirmarse, no tiene una base epistemológica, por lo menos técnicamente hablando.

En efecto, en términos de la filosofía analítica del lenguaje ordinario, toda calificación de una expresión deriva, en último término, de su uso. De ahí que, dependiendo del contexto, un mismo fonema o grafema pueda tener una diversa significación, en tanto ninguna de ellas (significaciones) suponga una suerte de lenguaje privado ${ }^{29}$. Eso sí, los usos no son inmunes a las prácticas lingüísticas y en ellas los actos del lenguaje aparecen vinculados a expresiones performativas específicas. De ahí que las palabras (en

${ }^{29}$ Wittgenstein, Ludwig, Investigaciones filosóficas (trad. Jesús Padilla, Madrid, Ed. Trotta), pp. 83-85; 137-145. 
sentido amplio, expresiones lingüísticas) tengan un poder constitutivo y que con ellas podamos no solo comunicar, sino también hacer $\operatorname{cosas}^{30} \cdot$ ¿ $Y$ qué hacemos? Podemos simplemente comunicar (función locutoria del acto); podemos plasmar una cierta intención en la expresión (contenido ilocutorio del acto), o podemos producir una respuesta (esperada o no) en el receptor de nuestra expresión (función perlocutoria del acto). En este juego del lenguaje, con todo, la elección de la expresión no es inocua (pues hay expresiones que son realizativas y otras descriptivas, y aún dentro de las primeras hay lugar para distinciones adicionales: expresiones judicativas, ejercitativas, compromisorias, etc ${ }^{31}$. Pero claro, la sola posibilidad de agrupar semánticamente expresiones en alguna de estas categorías es indicativo que la expresión elegida por un emisor, dentro de una determinada comunidad lingüística, no puede ser simplemente redefinida por un uso (privado) no convencional. Y ello porque, aunque se acepte que el significado de una expresión deriva de su uso, ello no transforma a la idea de significado y uso en sinónimos. Y un buen ejemplo de ello, precisamente, lo podemos encontrar a propósito de las expresiones soeces. Pues, aunque tanto una obscenidad como su equivalente culto (una expresión irónica, por ejemplo) puedan tener el mismo significado, el uso de una y otra entraña un acto diferente: uno es una ofensa y la otra no ${ }^{32}$. En otras palabras, la expresión proferida por el trabajador en el caso que revisamos no es equivalente, por ejemplo, a su equivalente culto: "vaya qué jefe tan juicioso y considerado es usted”, u otra expresión similar.

Estas breves consideraciones analítico-epistemológicas sirven para mostrar las dificultades que supone justificar, en este caso, la valoración de la prueba judicial desde una perspectiva únicamente epistemológica.

Por lo que venimos diciendo, resulta bastante claro que no basta la prueba de la verdad de los hechos (brutos) para que ellos ingresen al derecho como supuestos normativos. Por esto no debe extrañar que unos mismos hechos (probados) puedan dar lugar a diferentes relatos y diferentes relatos también a subsunciones normativas diversas (calificaciones) ${ }^{33}$. Por lo

${ }^{30}$ Austin, John, Como hacer cosas con palabras (trad. Genaro Carrió y Eduardo Rabossi, Barcelona, Paidós, 2016), pp. 155-166.

${ }^{31}$ Austin, cit. (n. 30), pp. 131.140; 213.

${ }^{32}$ Searle, John, Actos de habla (trad. Luis Valdés, 9a ed., Madrid, Cátedra, 2017), p. 185 fine.

${ }^{33}$ Esta afirmación también se puede encontrar en los partidarios de la teoría racionalista de la prueba, véase a este respecto TARUfFo, Michele, Narrativas Judiciales, en Revista de Derecho Valdivia vol. 20, n. ${ }^{\circ} 1$ (2007), pp. 231-270. Abandonando los contornos de la prueba judicial, pero aún de manera más intensa véase Kennedy, Duncan, Izquierda y Derecho (trad. Guillermo Moro, Buenos Aires, Siglo XX, 2010), pp. 27-84. 
mismo, nos parece, que para comprender el trasfondo del razonamiento probatorio presente en las resoluciones judiciales hay que atender más allá de la verdad del hecho al contexto normativo-jurídico en el cual ellas se producen. Y esto nos conduce directamente a algunos de los elementos estructurales que hemos encasillado en nuestro esquema.

\section{Hacia una amplación del concepto. Otro punto de partida TEÓRICO PARA LA APREHENSIÓN DE LA IDEA DE SANA CRÍTICA}

Afirmar que sólo la verdad ${ }^{34}$ es el valor rector (absoluto) en la ponderación de la prueba judicial nos parece inadecuado. Ello por dos razones. La primera, como ha mostrado con acierto Alex Stein, es que en materia de ponderación de la prueba judicial las consideraciones únicamente epistemológicas no ofrecen la mejor explicación. Pues, las más de las veces, lo que está en juego en la prueba judicial es la determinación del quantum probatorio deseable para satisfacer una repartición adecuada o equitativa de los riesgos de error (inevitables en todo proceso judicial), cuestión más bien de naturaleza moral (o política) que epistemológica. En otros términos, como el propio Stein lo ha sintetizado: "morality picks up what the epistemology leaves off" ${ }^{35}$.

La segunda razón tiene que ver con el contexto normativo dentro del cual la prueba judicial se desarrolla. Los teóricos de la prueba judicial (de la tradición racionalista) parecen no prestar mayor atención a un aspecto que desde siempre ha sido relevante para los teóricos del proceso: la fase probatoria está al servicio del proceso judicial y sus fines; no al revés ${ }^{36}$.

${ }^{34}$ Dejamos fuera de nuestra consideración la cuestión epistemológico-filosófica más general sobre el problema de la verdad y su obtención. Para una aproximación sobre el particular y desde la perspectiva de la teoría del derecho probatorio, véase Damaska, Mirjan, El Derecho Porbatorio a la Deriva (trad. Joan Picó e Junoy, Madrid, Marcial Pons, 2015), p. 101, n. 41.

${ }^{35}$ SteIn, Alex, Fundation of Evidence (N.Y., Oxford University Press, 2008), p. 12.

${ }^{36}$ Este problema ha sido advertido de forma aguda por Juan Carlos Bayón al señalar que, más allá de los indudables méritos de la tradición racionalista de la prueba judicial, ésta no ha reparado en el ajuste normativo que ha de buscarse entre las tesis que la propia tradición acepta: "la primera, que el proceso se orienta a la búsqueda de la verdad, si bien la naturaleza inductiva de los razonamientos probatorios hace que el resultado de la prueba no garantice la certeza absoluta. La segunda, que, aunque el proceso se oriente a la búsqueda de la verdad, al derecho no le interesa sólo la averiguación de la verdad, sino también la consecución de otros fines que pueden justificar la introducción de normas sobre la actividad probatoria, sobre los medios de prueba admisibles o sobre el resultado probatorio mismo que cabría calificar como 'contra-epistémicas' (en el sentido de que introducirían 
Ahora bien, si la teoría racionalista de la prueba judicial, más allá de sus indiscutibles aportes al derecho probatorio, no es suficiente para dar cumplida cuenta del fenómeno, es necesario explorar otras alternativas. En este sentido existen varias teorías que vienen a complementar, desde una perspectiva normativa, las aportaciones de la teoría racionalista. Algunas provienen de la tradición del derecho procesal y otras, poco a poco, se comienzan a abrir paso dentro de la propia tradición racionalista de la prueba. Para concluir esta investigación, revisaremos dos de estas propuestas. Desde la perspectiva procesal, la realizada por Enrique M. Falcón. Desde la perspectiva de la teoría racionalista, la desarrollada por Daniel González Lagier. En ambos casos, restringiremos nuestro análisis a la cuestión de la valoración de la prueba.

\section{Enrique Falcón y su teoría procesal de la sana crítica}

Para Falcón, la sana crítica es un régimen de ponderación de la prueba judicial comprehensivo de todo sistema de ponderación de la evidencia. En tal sentido, Falcón afirma que incluso los principios de la prueba tasada forman parte de la sana crítica ${ }^{37}$. "En este camino -escribe- veremos que dentro de la concepción mencionada está incluida la prueba tasada y cualquier decisión a que se llegue que requiera un razonamiento libre de vicios, perfectamente argumentado y sostenido de modo coherente sobre medios de prueba con los que se ha arribado - por las mejores vías posibles conocidas- a la fijación de los hechos. Pero la apreciación judicial de las pruebas -si bien abreva en la ciencia, especialmente en su método para la determinación de la realidad, y toma la experiencia objetivada para integrar las lagunas del conocimiento científico- está ligada al derecho, y de tal

excepciones o desviaciones de diversos tipos respecto a lo que resultaría de seguir incondicionadamente los criterios generales de racionalidad epistémica)". BAYÓN, Juan Carlos, Epistemología, moral y prueba de los hechos: hacia un enfoque no benthamiano en Revista Jurídica Mario Alario D’ Filippo (2008), p. 23.

${ }^{37}$ Cuestión que, por cierto, ya había sido advertida por el propio Fiedrich Stein en su célebre El Conocimiento Privado del Juez. En dicha obra, refiriéndose a las máximas de experiencia en materia de ponderación de la prueba judicial, escribe: "Antiguamente, estas consideraciones y reflexiones estaban, en su mayor parte, reguladas legalmente. La teoría de la prueba legal sustituía la experiencia individual y la opinión del juez por ciertas 'experiencias promedio' (Durchschnittserfahrungen) sobre el valor de los medios de prueba y si bien el derecho vigente ha ampliado sustancialmente el campo de discrecionalidad judicial, renunciando por completo a influir en la apreciación del juez, el valor interno de aquellas reglas, injustamente calumniadas en el movimiento de reforma, se ha cuidado, sin embargo de que, aun sin coacción, sigan aplicándose". STEIN, Fiedrich, El Conocimiento privado del juez (Pamplona, Ediciones Universidad de Navarra, 1973), p. 46. 
modo responde también a los principios de la prueba, a la normativa de cada una de las ramas y a los fines que cada sistema procesal debe preservar en concordancia con el derecho positivo"38.

Pero no sólo se detiene este autor en una aproximación conceptual al sistema, sino que se atreve a realizar una distinción entre la sana crítica como régimen de ponderación y las reglas de la sana crítica como expresión particular de la idea. Y, finalmente, no nos decepciona y nos entrega un catálogo de reglas particulares de la sana crítica en materia civil y penal (ambos órdenes tomados en sentido amplio).

Conceptualmente las reglas de la sana crítica son aquellas que "están incluidas en las ciencias (experimentales, como la física; culturales, como la historia); en la técnica (como derivado necesario de la ciencia en su aplicación); en las reglas de la experiencia; en la lógica, por dos vías: como marco para las demás actividades científicas, técnicas o experimentales, y por la vía argumental en la exposición de la sentencia. Todos estos elementos están sometidos al marco de la normativa jurídica, cuyas reglas también integran la sana crítica" ${ }^{39}$.

En concreto, estas reglas son, en materia civil, que sólo se prueban los hechos alegados en tiempo y forma; solo se prueban los hechos controvertidos; si hay prueba legal ha de estarse a ella; los medios probatorios deben ordenarse de acuerdo a su fiabilidad; los hechos mismos a probar demandan ciertos medios probatorios en desmedro de otros; la ponderación de la prueba ha de ser comparativa y completa; si las pruebas no son suficiente se aplicarán las presunciones; como última ratio se aplicará la carga de la prueba; finalmente "habrá que narrar el desarrollo de la investigación y de las conclusiones sobre el conflicto de modo tal que el relato demuestre que se ha adquirido la certeza en virtud de un procedimiento racional controlable, donde también se podrá utilizar como elemento corroborante la conducta de las partes en el proceso" ${ }^{40}$.

Las reglas en materia penal son: examinar que la investigación haya sido realizada de modo que comprenda todos los hechos que motivan la causa, en toda su extensión, teniendo como norte la verdad material; la averiguación de los hechos puede dirigirse tanto hacia la realización de la acción como hacia el autor mismo de aquella; se deben aplicar en primer lugar las pruebas legales , si las hay; los medios de prueba deben organizarse de acuerdo a su fiabilidad; los medios de prueba han de hacer patente una relación causal de los hechos a probar; la ponderación de las pruebas debe

${ }^{38}$ Falcón, Enrique, Tratado de la prueba judicial, 1 (2a edición, Buenos Aires, Astrea, 2009), pp. 658-659.

${ }^{39}$ FALCON, cit. (n. 38), p. 669.

${ }^{40}$ FALCÓN, Cit. (n. 38), p. 684. 
ser comparativa y completa; a falta de pruebas se aplicarán presunciones $o$ indicios; en materia penal ha de estarse al principio in dubio pro reo; ha de efectuarse una exposición motivada de los hechos (tal como la hemos descrito a propósito de las reglas de la sana crítica en materia civil ${ }^{41}$.

No nos interesa en este momento discutir si el concepto de sana crítica propuesto por Falcón es o no adecuado. Si sus reglas, metodológicamente hablando, son correctas o derechamente existe en la teoría una confusión de planos normativo-fácticos que impiden ver las particularidades de un derecho probatorio independiente de sus límites normativos (sustantivos y procesales). Lo que nos parece interesante de esta propuesta es que de alguna forma capta lo que realmente acontece en la fase de prueba dado el diseño institucional en la que se desarrolla, y una prueba de ello es que el tratamiento que asigna a la ponderación conforme a la sana crítica en materia civil y penal es diferenciado. Y ello solo se explica porque el entramado normativo de uno y otro orden jurídico difieren entre sí.

En tal dirección Falcón insiste, con razón, en que es poco razonable aislar la fase probatoria de su contexto normativo, toda vez que todo el iter probatorio está sometido al marco de la normativa jurídica, cuyas reglas también integran la sana crítica. Y ello no se limita al mero entramado normativo procesal, sino (incluso a veces con mayor intensidad) al derecho sustantivo. Pues "en cierta manera el derecho material condiciona políticamente al derecho procesal que le corresponde" ${ }^{\prime 2}$.

2. González Lagier y su aproximación analitica a la conformación del material probatorio: enlaces y garantías deductivas probatorias

Para Daniel González la cuestión de la ponderación de la prueba judicial no puede ser explicada única y exclusivamente desde una perspectiva epistemológica, pues en ella es posible distinguir diversas estrategias o insumos teóricos que los jueces "usan" efectivamente en contextos normativos como "garantías" en sus deducciones con consecuencias jurídicas. Es decir, a la pregunta ¿cómo puede un juez vincular los hechos al derecho?, González responde: por lo menos de tres formas diversas. En primer lugar, puede funcionar como garantía de la deducción algún criterio empírico inductivo. En materia de familia, un buen ejemplo de esta estrategia se encuentra en la determinación de la paternidad. En estos casos el juez puede, mediante el informe de las pruebas de $\mathrm{ADN}$, arribar a una conclusión cuya garantía es precisamente una inducción empírica. En otros casos, el vínculo entre los hechos y las normas ha sido resuelto por el propio legislador. Este es

\footnotetext{
${ }^{41}$ FALCÓn, Cit. (n. 38), pp. 690-698.

${ }^{42}$ FalCón, Cit. (n. 38), p. 691.
} 
el caso de las presunciones, una de cuyas manifestaciones la podemos encontrar en el artículo 199 de Código Civil, que dispone que: "la negativa injustificada de una de las partes a practicarse el examen (pericia de ADN) hará presumir legalmente la paternidad o la maternidad, o la ausencia de ella, según corresponda. Se entenderá que hay negativa injustificada si, citada la parte dos veces, no concurre a la realización del examen. Para este efecto, las citaciones deberán efectuarse bajo apercibimiento de aplicarse la presunción señalada en el inciso anterior".

En tercer lugar, es posible que el juez atribuya consecuencias normativas a unos ciertos hechos mediante una vinculación (o garantía) conceptual. Vale decir, hay un concepto (que generalmente será de carácter difuso o indeterminado) que le permite al juez decidir si los hechos acreditados o presentados por las partes pueden o no ser calificados conforme a los elementos del concepto a fin de ser introducidos como supuesto fáctico de la norma jurídica.

Para efectos de lo que venimos diciendo (la comprensión adecuada de la valoración de la prueba judicial), nos parece un acierto de González Lagier la incorporación de garantías diversas a las empírico-inductivas. En estos casos, "el enlace es una norma (normalmente de origen legislativo o jurisprudencial) que establece que si se dan hechos como los descritos en las premisas (el hecho base), se debe dar por probada determinada hipótesis (el hecho consecuencia); podemos llamar a estas normas 'normas de presunción' o normas de valoración tasada de la prueba y a estas inferencias, inferencias probatorias normativas". O bien, "la conexión viene establecida por una definición o regla conceptual, que establece que los hechos del tipo de los descritos en la hipótesis 'cuentan como' (esto es, son subsumibles en) una cierta categoría de hechos (una acción, una intención, una relación causal, etc.). En estos casos, lo que está en juego no es tanto la ocurrencia o no de un determinado hecho, sino su 'interpretación', es decir, su clasificación dentro de una u otra categoría genérica de hechos" ${ }^{43}$.

${ }^{43}$ González Lagier, Daniel, Distinciones, estipulaciones y sospechas sobre los criterios de valoración y los estándares de prueba, en BENFELD, Johann y LARROUCAU Jorge, La sana crítica bajo sospecha, cit. (n. 3), pp. 16-18. Este trabajo de González puede ser considerado una exposición refinada de las ideas que este autor ha desarrollado durante los últimos años. Sobre el particular nos parecen relevantes como trasfondo de su propuesta especialmente sus siguientes trabajos: GonZÁLEZ LAGIER, Daniel, Hechos y argumentos (racionalidad epistemológica y prueba de los hechos en el proceso penal) (I), en Jueces para la democracia n. 31 (2003), pp. 17-26; GonZÁlez Lagier, Daniel, Hechos y argumentos (racionalidad epistemológica y prueba de los hechos en el proceso penal) (II), en Jueces para la democracia no 43 (2003), pp. 35-50. González Lagier, Daniel, Quaestio facti. Ensayos sobre prueba, causalidad y acción (Lima, Palestra, 2005), pp. 231. En estos dos trabajos, González realiza un 
En consecuencia, la ponderación de la prueba judicial puede tener diversas garantías: unas serán de naturaleza inductivo/empíricas que él no duda en calificar como de "sana crítica" propiamente tal; otras serán de naturaleza normativo jurídicas, éstas son las presunciones (sobre todo las de derecho); y finalmente existen también enlaces conceptuales. Generalmente éstos dependerán de manera determinante del contexto normativo mismo.

Ahora bien, volviendo a nuestro ejemplo (caso laboral), para nosotros resulta claro que en la especie estamos en presencia de una conexión de naturaleza conceptual. Esto quiere decir que el conjunto de elementos probatorios aportados por las partes es susceptible de ser subsumido en la hipótesis normativa en la medida en que se aproxime al contenido del concepto (en este caso el de "injuria o vía de hecho"). En este sentido, como dice González, no es tan importante la efectiva ocurrencia o no de unos hechos (la obscenidad proferida por el trabajador), sino la definición misma del concepto, pues a fin de cuentas es ésta y no los hechos la que permite la subsunción de un determinado conjunto de proposiciones fácticas dentro del supuesto. Y en este caso, qué duda cabe, el sentido mismo del concepto depende del contexto normativo.

Cuando se parte de la base que el enlace, por lo menos en este caso, es de naturaleza conceptual, resulta más simple explicar por qué el tribunal $a$ quo y ad quem pudieron tener, legítimamente, una interpretación diversa a la del demandado (calificación). Ambos, a nuestro entender, valoraron la prueba de manera libre, pero la determinación de la aptitud del conjunto probatorio para garantizar la verificación del supuesto llevó a los tribunales, de manera legítima y racional, en una dirección diversa las pretensiones del empleador. Ahora bien, la no calificación de injuria o vía de hecho en la especie, nos parece, se explica por el contexto normativo en el que el tribunal debe evaluar la evidencia (en este caso influenciado por el principio tuitivo del trabajador).

Por todo lo anterior, nos parece más probable que las proposiciones probatorias que concitarán en materia procesal laboral la adhesión de los jueces serán aquellas que, en concordancia con el principio rector de protección, tuitivo o también llamado de favor del trabajador, busquen la tutela efectiva de los derechos del trabajador más que la averiguación de la verdad de los hechos (brutos acreditados) dentro de un proceso ${ }^{44}$.

fino análisis desde una perspectiva epistemológica de lo que constituiría garantías deductivas e inductivas. No viene al caso que aquí detallemos las "reglas de sana crítica" que desde esa perspectiva es posible identificar. Aunque sí debemos hacer notar que el análisis que efectúa González sobre el particular es de un indudable valor $y$, por cierto, podría constituir un precioso insumo para el razonamiento judicial.

${ }^{44}$ Para un estudio más acabado sobre el particular, véase Arellano, Pablo y 
Y es esto precisamente lo que, nos parece, se observa en el caso "Órdenes Abarca v/s Electricidad Gobante S.A”.

\section{CONCLUSIONES}

Al comenzar estas páginas hemos afirmado que, aunque la sana crítica es el régimen de ponderación general de la prueba en materia penal, labora y de familia, la diversa manera en que el régimen de ponderación aparece modelado normativamente en dichos procedimientos hace surgir la pregunta sobre si realmente el concepto canónico que se tiene sobre el mismo es el adecuado para lograr su comprensión.

En este orden de cosas es posible advertir dos respuestas. Una afirmativa, que se mantiene muy próxima a la idea tradicional sobre la sana crítica y que la entiende como un régimen de ponderación libre de la prueba, de base racional, y cuyo sustento directo es la aplicación de los principios de la lógica, las máximas de la experiencia y los conocimientos científicamente afianzados. Esta es la posición que adopta (muy a grandes rasgos) la teoría racionalista de la prueba, que postula un compromiso irrestricto con la búsqueda de la verdad en los procedimientos judiciales. En esta empresa, la teoría racionalista usa los elementos tradicionalmente presentes en el concepto de sana crítica para introducir, a propósito de los mismos, recursos exorbitantes al derecho. Insumos que, las más de las veces, son tomados a préstamo desde las disciplinas científicas vinculadas con la teoría del conocimiento y sus criterios de validación (epistemología, gnoseología, psicología, etc.).

Las aportaciones de la teoría racionalista de la prueba son muchas y significativas. Como hemos señalado más arriba, esta aproximación a la sana crítica ha tenido la virtud de conectar de forma razonable las exigencias de justificación racional de las decisiones judiciales con los fundamentos del estado de derecho (igualdad ante la ley y debido proceso) y con la idea de democracia (y su exigencia de justicia), mediante la promoción del establecimiento de ciertos baremos de racionalidad teórico-práctica en las fundamentaciones de las sentencias judiciales. También ha tenido, desde el punto de vista epistemológico, el mérito de clarificar metodológicamente, en un proceso de desagregación conceptual, cuáles elementos del extrarradio jurídico (epistemológicamente hablando) han de servir como recursos para la averiguación de la verdad de los hechos en un proceso judicial.

Sin embargo, con todas sus bondades no nos parece suficiente para desactivar la crítica que A. Stein realiza de la misma en sólo una línea:

BENFELD, Johann, cit. (n. 3), pp. 12-22. 
"la moralidad es la que recoge lo que la epistemología abandona". Es decir, ninguna aproximación sólo epistemológica tiene la aptitud suficiente para explicar, dentro de los contornos del derecho probatorio, las opciones políticas y morales que determinan normativamente los principios y los estándares de la prueba en sede jurisdiccional.

La segunda respuesta posible a la pregunta sobre si la aproximación tradicional al concepto de sana crítica es la adecuada es negativa. Con esto no se quiere decir que la sana crítica como régimen de ponderación judicial sea inadecuado, sino simplemente que para una correcta comprensión de la misma hay que abandonar los contornos de la epistemología y ampliar el concepto a los elementos normativos dentro del cual la prueba judicial tiene lugar. Esta estrategia no sólo explica las opciones normativas por la distribución de riegos (que es lo que preocupa a A. Stein), sino también pone de manifiesto que una cosa es la prueba de los hechos mismos (o de las proposiciones empíricas, si se prefiere) y otra diversa es la valoración de la prueba judicial. Y esto es determinante para comprender la sana crítica en los diversos contextos normativos en los cuales se la emplea (penal, laboral, derecho de familia), pues como hemos tenido ocasión de ver a propósito de la sentencia laboral que hemos comentado a modo ejemplar, unos mismo hechos probados pueden servir de insumo para la construcción de relatos alternativos con base empírica que, sin embargo, pueden ser subsumidos en diferentes supuestos normativos que es precisamente el problema de la "valoración de la prueba", más allá de la verificación de las proposiciones empíricas ${ }^{45}$.

Ahora bien, de qué manera es posible ampliar el concepto es una cuestión también controvertida. Una opción, como hemos estudiado es anclar el concepto dentro de la propia tradición procesalista a la manera que lo hace Falcón ${ }^{46}$. Otra estrategia, es circunscribir el concepto dentro de los diversos recursos de ponderación de la prueba judicial (inductivo/ empíricos; normativo/jurídicos; conceptual/normativos) como lo propone González Lagier. A nosotros, con todo, cualquiera de estas dos estrategias

${ }^{45}$ En este punto tampoco pretendemos estar descubriendo América. De hecho, existen actualmente teorías sobre epistemología jurídica que avanzan en esta dirección. Se trata de las llamadas teorías postpositivistas, sean éstas de naturaleza coherentista o consensualista, que apuntan precisamente a poner de manifiesto los aspectos normativo contextuales en los que los hechos ingresan en un procedimiento judicial. Para una explicación breve sobre estas teorías (aunque desde un punto de vista crítico de las mismas) véase, GASCÓN, Marina, cit. (nº12), pp. 35-37; 50-59.

${ }^{46}$ En esta dirección véase también, BENFELD, Johann, La sana crítica y el olvido de las reglas de la sana crítica, en Revista de Derecho, Valdivia vol. 31, n. ${ }^{\circ}$ (2018), pp. 303-325. 
nos parece más adecuada que la mera aproximación epistemológica que, como hemos dicho, no logra describir el fenómeno de la prueba judicial sino más bien indicarnos cómo debiese ser el mismo para purgarlo de sus supuestas patologías epistémicas.

\section{BIBLIOGRAFÍA}

Accatino, Daniela, Legal Evidence Theory: Are We All "Rationalists" Now? en Revus, no 40 (2020), pp. 85-101.

Anderson, Terence, Schum, David y Twining, William, Análisis de prueba (trad. de Daniela Accatino, Claudio Agüero, Federico Arena, Flavia Carbonell, Rodrigo Coloma, Juan Pablo Fassnidge y Jorge Larroucau, Madrid, Marcial Pons, 2015 [2005]).

Anscombe, G., On Brute Facts, en Analysis vol 18, no 3 (1958), pp. 69-72.

Arellano, Pablo y Benfeld, Johann, Reflexiones sobre el principio de protección al trabajador y su influencia en el ámbito sustantivo y procesal del derecho laboral en Revista Chilena de Derecho y Tecnología vol. 6, no 2 (2107), pp. 3-24.

Austin, John, Como hacer cosas con palabras (trad. Genaro Carrió y Eduardo Rabossi, Barcelona, Paidós, 2016).

BAEZA, Gloria, El interés superior del niño: derecho de rango constitucional, su recepción en la legislación nacional y aplicación en la jurisprudencia, en Revista Chilena de Derecho vol. 28, no 2 (2001), pp. 335-362.

BAYÓN, Juan Carlos, Epistemología, moral y prueba de los hechos: hacia un enfoque no benthamiano en Revista Juridica Mario Alario D’ Filippo (2008), pp. 15-34.

BENFELD, Johann, La sana crítica y el olvido de las reglas de la sana critica, en Revista de Derecho, Valdivia vol. 31, n. ${ }^{\circ} 1$ (2018), pp. 303-325.

Bentham, Jeremy, Tratado de las Pruebas Judiciales (Traducción C.M.V., Buenos Aires, Valletta Ediciones, 2008).

Carbonell, Flavia, Sana crítica y razonamiento judicial, en Benfeld, Johann y LarRouCAU, Jorge (Eds.), La sana crítica bajo sospecha (Valparaíso, Ediciones Universitarias de Valparaíso, 2018).

Cerda San Martín, Rodrigo, Valoración de la prueba. Sana crítica (Santiago, Librotecnia, 2008).

Coloma Correa, Rodrigo, Estándares de prueba y juicios por violaciones a los Derechos Humanos, en Revista de Derecho vol. 22, no 2 (2009), pp. 205-229.

Coloma Correa, Rodrigo, La caida del argumento de autoridad y el ascenso de la sana crítica, en Revista de Derecho de Valdivia vol. 25, n. ${ }^{\circ} 2$ (2012), pp. 207-228.

Coloma Correa, Rodrigo, Realmente importa la sana critica, en Revista Chilena de Derecho vol. 39, n. 3 (2012), pp. 753-781.

Coloma, Rodrigo - Agüero, Claudio, Fragmento de un imaginario judicial de la sana crítica, en Ius et Praxis 20, n.o 2 (2014), pp. 375-414.

Coloma, Rodrigo - AGÜERo, Claudio, Lógica, ciencia y experiencia en la valoración de la prueba, en Revista Chilena de Derecho vol. 41, n. ${ }^{\circ} 2$ (2014), pp. 673-703.

Couture, Eduardo, Fundamentos del Derecho Procesal Civil ( $3^{a}$ edición, Buenos Aires, Roque de Palma Editor, 1958).

DAMASKA, Mirjan, El Derecho probatorio a la deriva (trad. Joan Picó e Junoy, Madrid, Marcial Pons, 2015). 
Falcón, Enrique, Tratado de la prueba judicial, 1 (2a edición, Buenos Aires, Astrea, 2009).

FERrer, Jordi, La valoración racional de la prueba (Madrid, Marcial Pons, 2007).

Ferrer, Jordi, Motivación y Racionalidad de la Prueba (Lima, Ed. Jurídica Grijley, 2016).

Fuentes Maureira, Claudio, La persistencia de la prueba legal en la judicatura de familia, en Revista de Derecho Coquimbo vol. 18, n. ${ }^{\circ} 1$ (2011), pp. 119-145.

GAMONAL, Sergio, El derecho procesal del trabajo, sus caracteres y el principio de igualdad por compensación, en Revista de Derecho Laboral y Seguridad Social vol. 3, n. ${ }^{\circ}$ (2015), pp. 89-119.

Gascón, Marina, Los Hechos en el Derecho, (Madrid, Marcial Pons, 2010).

GonZÁlez Lagier, Daniel, Hechos y argumentos (racionalidad epistemológica y prueba de los hechos en el proceso penal) I, en Jueces para la democracia 31 (2003), pp. 17-26.

GONZÁlez LAGIER, Daniel, Hechos y argumentos (racionalidad epistemológica y prueba de los hechos en el proceso penal) II, en Jueces para la democracia 43 (2003), pp. 35-50.

González Lagier, Daniel, Quaestio facti. Ensayos sobre prueba, causalidad y acción (Lima, Palestra, 2005).

González Lagier, Daniel, Distinciones, estipulaciones y sospechas sobre los criterios de valoración y los estándares de prueba, en BENFELD, Johann y LARROUCAU Jorge, La Sana Crítica Bajo Sospecha, (Valparaíso, Ediciones Universitarias de Valparaíso, 2018), pp. 16-18.

Kennedy, Duncan, Izquierda y Derecho (trad. Guillermo Moro, Buenos Aires, Siglo XX, 2010).

Laso Cordero, Jaime, Lógica y sana crítica, en Revista Chilena de Derecho 36, n. ${ }^{\circ} 1$ (2009), 143-164.

LAUDAN, Larry, Verdad, errory proceso penal (trad. Carmen Vásquez y Edgar Aguilera, Madrid, 2013).

LEMPERT, Richard, The New Evidence Scholarship: Analyzing the Process of Proof, en Boston University Law Review, no 66 (1986), pp. 439-477.

Lepin Molina, Cristian, Breve estudio sobre la sana crítica, en Gaceta Jurídica 319 (2007), pp. 7-13.

López Díaz, Carlos, Apreciación de la prueba por la sana crítica y procedencia del recurso de casación en el fondo en los procesos ante los tribunales de familia, en Gaceta Jurídica 294 (2004), pp. 22-27.

Maturana Baeza, Javier, Sana critica (Santiago, Thomson Reuters, 2014).

SeArle, John, Actos de habla (trad. Luis Valdés, 9o ed., Madrid, Cátedra, 2017).

STEIN, Fiedrich, El Conocimiento Privado del Juez, (Pamplona, Ediciones Universidad de Navarra, 1973).

Stein, Alex, Fundation of Evidence (New York, Oxford University Press, 2008).

TARuffo, Michele, Narrativas Judiciales, en Revista de Derecho Valdivia vol. 20, n. ${ }^{\circ}$ 1 (2007), pp. 231-270.

Taruffo, Michele, La Prueba (trad. L. Manríquez, J. Ferrer, Madrid, Marcial Pons, 2008).

TAruffo, Michele, Simplemente la verdad (trad. Daniela Accatino, Madrid, Marcial Pons, 2010), p. 138.

TwinIng, William, Rethinking Evidence. Exploratory Essays (2a edición, Cambridge, Cambridge University Press, 2006).

Wittgenstein, Ludwig, Investigaciones filosóficas (trad. Jesús Padilla, Madrid, Trotta, 2017). 